\title{
Environmental uses of zeolites in Ethiopia
}

\author{
Isabel Díaz
}

Instituto de Catálisis y Petroleoquímica, CSIC

c/ Marie Curie 2, 28049 Madrid

Email:idiaz@icp.csic.es 


\begin{abstract}
In the past six years we have been intensively collaborating with the Chemistry Department of Addis Ababa University as well as Haramaya University to bust scientific knowledge related to zeolites and zeolite applications. Initially, we teamed up with geologists and government actors in the mining sectors; as a result we got access to natural zeolites from the north of the country, as well as other industrial minerals such as kaolin. In parallel we developed research activities in the use of zeolites as adsorbents and in catalytic processes related to environmental applications of necessity in Ethiopia. In the first part of this paper I will describe two examples of adsorption processes using mineral resources: one is a natural stilbite used to develop an adsorbent to remove fluoride from drinking waters; and the second one uses virgin kaolin to prepare a synthetic zeolite 4A that we used to remove chromium from tannery wastewaters. Finally, two catalytic examples will be described: in the first one we tackled the photocatalytic degradation of dyes from textile industries using Ti-modified natural and synthetic zeolites, and in the second one we used modified mordenites, both natural and synthetic, for the conversion of glucose into 5-HMF.
\end{abstract}

Keywords: Ethiopia; Zeolites; fluoride; chromium; kaolin 


\section{Introduction}

Despite scattered findings of zeolites deposits around Ethiopia, no efforts have been made in exploring deeply the presence and potential industrial interest of zeolites in this country. Research and development of scientific knowledge related to zeolites coupled with capacity building may contribute to gain the interest of stakeholders. With this aim, in the past six years we have been intensively collaborating with the Chemistry Department of Addis Ababa University as well as Haramaya University to bridge this gap. In the same line, the Research and Development Directorate of the Ministry of Mines was interested in exploring new applications of industrial interest involving other Industrial Minerals already under exploitation along the country, such as bentonite and kaolinite. When we surveyed the accessible Ethiopian industries, we learnt that the main demand of zeolites was as adsorbents or ion exchangers in water and wastewater treatments.

Zeolites are crystalline microporous aluminosilicates with a defined three-dimensional structure composed by Silicon and Aluminium tetrahedra which share oxygen vertices. These tetrahedral units may connect in different fashion giving yield to a wide variety of topologies and thus forming a wide range of porous structures. Zeolites are found in nature, in volcanic areas all over the world, but they can also be synthesized in the laboratory. In the case of natural zeolites, the inorganic network is composed of silicon and aluminium in such a way that the final network charge is negative, and thus generating the necesity of extra framework cations that compensate the charge. This counter cations are located in the pores or cavities of the zeolites. These counter ions are known as extra framework cations, since they are not directly bonded to the inorganic network, but are retained by steric effects and electrostatic interactions. This type of 
interactions allows for an exceptional mobility characteristic of the main applications of zeolites in industry as cation exchangers in the sectors of water purification and detergents. Application of natural zeolites for water and wastewater treatment by adsorption is still a promising technology in environmental cleaning processes. Adsorption properties of natural zeolites in comparison with other chemical and biological processes have the advantage of removing impurities also at relatively low concentrations and allow conservation of water chemistry.

According to the report of 2010, the global market for natural zeolites grew from 3.98 million to 5.5 million tons and in the same time period, the usage of synthetic zeolites was projected to reach 1.86 million tones [1]. While $90 \%$ of natural zeolites are mainly applied in the construction industry, the remaining $10 \%$ find uses in processes such as waste water treatment, animal feeding, horticulture, odor control and other miscellaneous applications. However, due to the large presence of impurities, natural zeolites have limited applications for industrial processes where synthetic zeolites are preferred.

In Ethiopia the incredible economic growth of the past ten years is mainly due to the development of new manufacturing plants including textile and tanning factories. However, the environmental protection and WASH (Water, Sanitation and Hygiene) Programs are not running as fast as the increasing industrial development. More potentially polluted water will eventually become accessible as drinking water points. In addition to this, there are already geogenic contaminants such as Fluoride and Arsenic which are already polluting drinking waters all over the world. Fluoride contamination of groundwater is a spontaneous process occurring in volcanic areas where the groundwater passes through F-containing volcanic rocks such as fluorite $\left(\mathrm{CaF}_{2}\right)$, fluoroapatite $\left(\mathrm{Ca}_{5}\left(\mathrm{PO}_{4}\right)_{3} \mathrm{~F}\right)$ and cryolite $\left(\mathrm{Na}_{3} \mathrm{AlF}_{6}\right)$. In small concentrations, it is 
beneficial for children in strengthening bones and preventing tooth decay [2]. However, an excessive intake of fluoride leads to dental or skeletal fluorosis and its continuous intake in time may lead to cancer, osteosclerosis or even liver and kidney damages in human beings [3]. In Ethiopia more than 8 million people in rural areas of the Rift Valley, are at high risk due to a regular exposure to fluoride contaminated groundwater, the largest source of water for human consumption [4].

The leather and textile industries are becoming one of the major industrial sectors in Ethiopia that contributes substantially towards the national economy. According to the Ethiopian leather evaluation final report by UNIDO (2012) there were 26 tanneries in Ethiopia and almost all of them employ chrome tanning [5]. The wastewater of tanning process is usually discharged, without proper treatment, into the sewerage system leading to a health and environmental problem [6]. The Ethiopian Environmental Pollution Control Proclamation No.300/2002 has limited the total chromium and Cr(VI) from tannery wastewater to the environment to $2 \mathrm{mg} / \mathrm{L}$ and $0.1 \mathrm{mg} / \mathrm{L}$, respectively.

In the case of Ethiopian Textile Industry, the Development Institute (ETIDI), has reported that more than $14,250,406 \mathrm{Kg}$ of various types of dyes and chemicals have been used by their factories in 2011. The Ethiopian Environmental Protection Authority (EPA) as an environmental regulatory and monitoring body is setting the laws on environmental pollution control which is generating an urgent demand for treatment of textile wastewater. A wastewater with high concentrations in chromium salts and dyes may be pro-carcinogenic and exhibit high level of toxicity [7].

In our work, we have emphasized the use of natural or synthetic zeolites for environmental remediation in the lines described above. In this manuscript, a forth section is included devoted to the use of zeolites in green chemistry (the conversion of glucose into of 5-HMF) in an attempt to provide other contribution to the sustainable 
industrial development in which zeolites may play a role. The information included in this manuscript is a small review of the work done in these years related to these uses already mentioned. Four Phd Thesis were developed in the course of the research exposed in this manuscript. Six more Phd Thesis are currently in progress and directly or indirectly related to the use of Zeolites in the Chemistry Departments of Haramaya and Addis Ababa Universities in Ethiopia.

\section{Results and Discussions}

Zeolites are a vast natural resource in Ethiopia that remains unexploited due to lack of scientific knowledge and available manpower with a geology background and means to initiate the systematic exploitation of this resource. Previous studies showed abundant resources of mordenite and clinoptilolite near Nazret [8] and philipsite and also clinoptilolite in the Awassa area [9]. In our attempt to thrive the exploitation and further involvement of zeolites in the chemical industry of Ethiopia, we have been engaged for the past six years in academic activities with the Inorganic Stream of the Chemistry Department at Addis Ababa University aiming to fill up the gap developing capacities in the scientific knowledge related to zeolites. From research point of view, we devoted extra efforts in developing new research lines using local knowledge in electrochemistry [10], synthesis of coordination compounds [11-13] and green chemistry [14-17]. At the same time, we have collaborated with the Earth Science Department of Addis Ababa University as well as with the Directorate of Research and Development of the Ministry of Mines of Ethiopia in order to survey the potential deposits of natural zeolites in the country. One of the collaborative projects developed in the north region of the country, yielded several zeolitic phases and at least one highly-pure large deposit of stilbite could be identified [18]. Besides, we have devoted large efforts in adding value to other 
Industrial Minerals, such as Bentonite [19-21] and Kaolinite [22, 23], with known deposits at early stages of exploitation. On our side, we analyzed the samples and evaluated potential applications that could justify their commercial exploitation. The initial identification of the zeolitic phases was carried out by XRD and ICP. Depending on the type of zeolite, purity and chemical composition, the natural zeolites were tested in two groups of applications: adsorption or catalysis. Adsorption processes involved defluoridation of drinking waters, and removal of chromium from tannery wastewater. Catalytic processes involved photodegradation of dyes from textile wastewaters and the conversion of glucose to 5-HMF.

\subsection{Zeolitic Phases devoted to adsorption}

Two cases are presented in the following paragraphs of natural resources employed in adsorption processes devoted to environmental remediation.

\subsubsection{Defluoridation of drinking water.}

It has been reported that the consumption of fluorinated water remains above the recommended healthy limit of $1.0 \mathrm{mg} / \mathrm{L}$ in the majority of rural areas in developing countries. Thus, more than 260 million people all over the world are exposed to dental or skeletal fluorosis, becoming an endemic health problem in at least 25 countries: fourteen in Africa including Ethiopia, eight in Asia, and six in America [24]. In countries or places where the infrastructure allows for other sources of clean water, fluorosis could be easily mitigated by simply avoiding the consumption of fluorinated water. However, there are millions of inhabitants in rural areas that can only access to polluted water where defluoridation of water is the only measure to prevent health problems related to fluoride. Over the years, a large number of materials and methods have been proposed at least to minimize the effect of the fluoride problem. Commonly 
used technologies of defluoridation involve the use of adsorbents either aluminium or calcium phosphate based. As anion exchangers, hydrotalcites (also called layered double hydroxides or LDH) are also potential high capacity materials [25, 26]. We investigated the fluoride uptake by layered double hydroxide (LDH) and calcined layered double hydroxide (CLDH). Furthermore, practical use of these synthetic minerals was studied in continuous mini-column experiments using groundwater from the Ethiopian Rift Valley. CLDH have shown maximum removal capacity of $222 \mathrm{mg} \mathrm{F}^{-}$ /g from synthetic aqueous solution, which is higher than the expected value of $144 \mathrm{mg}$ $\mathrm{F}^{-} / \mathrm{g}$, and maximum fluoride removal capacity of $2.2 \mathrm{mg} / \mathrm{g}$ with groundwater from the Ethiopian Rift Valley. The main disadvantage of this type of materials is that they dissolved under the real conditions of groundwater, leading to high levels of dissolved aluminium to the drinking water as well as a notable increase of the final $\mathrm{pH}$. In the case of Ethiopia, the adsorbent currently implemented in the rural area is bone char, obtained by burning at high temperature animal bones obtained from butchers. Most of the remaining solid after burning is hydroxyapatite, the mineral component of bones, which shows some capacity to adsorb fluoride. To obtain the bone char, several Tonnes of animal bones are charred at $400{ }^{\circ} \mathrm{C}$ for 10 days in a burning house used as furnace, then, the resulting heterogeneous charred material is hand-picked to separate the most suitable charred bones, because the temperature inside the burning house is quite inhomogeneous and part of the organic material is burned in places inside the burning chamber where the temperature is excessively low, leading to an incomplete calcination of the organic matter. On the other side, if the burning temperature is too high, the defluoridation performance of the charred bones is very poor. Therefore, this is a complex process which needs to be performed very carefully. This technology has some serious limitations, among them the limited availability of bones, the complexity of the 
calcination process, the high consumption of fuel and the need of a washing process after the charring which involves harsh chemicals (sulfuric acid and caustic soda). Moreover, there are certain controversial social issues, related to religious and cultural beliefs linked to the origin of the adsorbent. However, the main drawback of this technology consists in its poor efficiency to remove fluoride from real groundwater to achieve the $1.5 \mathrm{mg} / \mathrm{L}$ WHO limit.

Zeolites are cationic exchangers thus their activity in raw is rather low [27]. Attempts to form composites based on zeolites require a compromise in the efficiency of the mechanical strength of the composite while maintaining good fluoride removal capacity [28]. The most pure zeolitic phase obtain in the geological screening in the north of Ethiopia was found to be Stilbite, a mineral belonging to the STI family, which contains a mixture of $\mathrm{Na}$ and $\mathrm{Ca}$ as extra-framework cations. The general formula of stilbite is $\left(\mathrm{Ca}_{4}, \mathrm{Na}\right)\left(\mathrm{H}_{2} \mathrm{O}\right)_{3} 0\left[\mathrm{Al}_{9} \mathrm{Si}_{27} \mathrm{O}_{72}\right]$, with a $\mathrm{Si} / \mathrm{Al}$ ratio close to 3 . The framework of stilbite (STI) is composed of two sets of connected channels, one of 10-membered rings, with dimensions of $5.0 \times 4.7 \AA$, and the other of 8-membered ring channels $(2.7$ x $5.6 \AA ̊$ ), conforming a cavity where $\mathrm{Ca}$ and $\mathrm{Na}$ cations are located, surrounded by water molecules [29]. The elemental composition of this Stilbite is given in Table 1. Taking the most abundant components, and assuming they belong to the stilbite mineral, we obtain a formula per STI unit cell of $\left(\mathrm{Na}_{0.94} \mathrm{~K}_{0.06}\right)\left(\mathrm{Ca}_{3.5} \mathrm{Mg}_{0.18}\right) \mathrm{Al}_{8.6} \mathrm{Si}_{27.4} \mathrm{O}_{72}$, very close to the general formula. The sum of the cationic charges $(+8.4)$ is very similar to the negative charges introduced by $\mathrm{Al}(-8.6)$, suggesting that these cations actually belong to the STI zeolite phase. With this high content of $\mathrm{Ca}$, we used this natural zeolite as a source of calcium ions for the growth of nanocrystals of hydroxyapatite (nHAp), thus producing a composite stilbite/nHAp material [30]. Interestingly, exposed to a suitable cation in solution, this stilbite exchanges the $\mathrm{Ca}^{2+}$ ions in a very slow and controlled 
way. This is due to the particular topology of this framework together with the particular interactions between $\mathrm{Ca}^{2+}$ and the wall which makes the diffusion towards the outer surface of the crystal difficult. Initially $\mathrm{Ca}^{2+}$ is exchanged by $\mathrm{NH}_{4}{ }^{+}$, then upon the release to the solution, and in the presence of $\mathrm{PO}_{4}{ }^{3-}$, allows the precipitation of hydroxyapatite on the zeolite surface with very small particle sizes. Further optimization of the $\mathrm{Ca}-\mathrm{NH}_{4}$ exchange through variations of temperature and time provided smaller nHAp crystals with increasingly higher $\mathrm{F}^{-}$uptake capacities [31]. This adsorbent has proven to be efficient in elimination of $\mathrm{F}^{-}$from real ground waters of Ethiopia. The use of easily accessible raw materials with high surface areas as support allows for an affordable technology. Besides, the growth of HAp on the external surface of the zeolites is carried out at room temperature without any extra addition of chemicals (autogenous $\mathrm{pH}$ around 8 ), reducing the production costs, unlike the most common precipitation methods of HAp which are usually carried out at high temperatures and at basic higher pHs. Table 1 collects the chemical composition of the optimized stilbite/nHAp composite in which the amount of hydroxyapatite is calculated based on the P content obtained by ICP Elemental Analysis following the equation 1:

$$
\text { HAp wt } \%=\mathrm{P} \text { wt } \%_{(\text {ICP) }} \times \frac{502}{93} \quad \text { [Equation. 1] }
$$

where 502 is the total molecular mass of HAp, and 93 is the molecular mass of $\mathrm{P}$ in HAp $\left(\mathrm{Ca}_{5}\left(\mathrm{PO}_{4}\right)_{3} \mathrm{OH}\right)$. Figure 1 shows the TEM and STEM/HAADF/EELS images of typical crystals of the composite. Conventional TEM images (Figure 1a) allowed observing the growth of small particles of nHAp that grew forming very thin fibres decorating the surface of the STI crystals. HAp nanocrystals are clearly appreciated in the images as very thin hairy crystals protruding from the STI homogeneous surface, 
linked to the zeolite crystals, which means that the surface of the stilbite acts as source of nucleation points. The chemical composition of these nanocrystals could be extracted using Electron Energy Loss Spectroscopy (EELS) (Figure 1b). STEM/HAADF/EELS mapping (Figure 1c) analysis performed over the area marked with a white rectangle clearly shows the crystallization of HAp on the external surface of the STI zeolite, distinguishable by $\mathrm{Ca}$ (in red colour) attached to the surface of the zeolite crystals, whose identifying element is $\mathrm{Si}$ (green colour). As can be observed in stilbite/nHAp composite samples, green colour $(\mathrm{Si})$ follows a sharp surface corresponding to the STI crystal, whereas red $(\mathrm{Ca})$ colour of HAp draws thin irregular forms on the surface of STI zeolite. In the course of our work, we used the concept of intrinsic capacity of HAp $\left(\mathrm{Q}_{\mathrm{e}(\mathrm{HAp})}\right)$, which is referred only to the percentage of HAp in the composite material, to describe the relative activity of the adsorbent material with respect to the amount of HAp, and was calculated following equation 2:

$$
\mathrm{Q}_{\mathrm{e}, \mathrm{HAp}}=\frac{\mathrm{C}_{\mathrm{o}}-\mathrm{C}_{\mathrm{t}}}{\text { Total dose } \times \frac{(\text { wt } \% \text { HAp })}{100}}
$$

We used this intrinsic capacity concept to compare the performance of our zeolite composite, stilbite/nHAp or nHAST, with an adsorbent that of bone char (BC). The active phase of this $\mathrm{BC}$ adsorbent is hydroxyapatite (HAp), similar to that of our composite [32]. Therefore, this comparison may bring information that allows us to analyse the feasibility of implementation of the nHAST adsorbent. The intrinsic HAp capacity of stilbite/nHAp, normalized to the amount of HAp on the adsorbent, is significantly higher $\left(9.15 \mathrm{mgF}^{-} / \mathrm{gHAp}\right)$ than that of bone char (1.08mgF/gHAp), showing a much higher $\mathrm{F}^{-}$-removal efficiency of HAp on the composite. This 
comparison is plotted in Figure 2 together with a new product found in the market and based on pure synthetic Hydroxyapatite. Synthetic pure HAp performs very well, removes about $98 \%$ fluoride from $5 \mathrm{mg} / \mathrm{L}$ initial fluoride concentrationat at $10 \mathrm{~g} / \mathrm{L}$ adorbent dose. This is slightly higher as compared to stilbite/nHAp (nHAST) and BC adsorbents with 94.6 and $92.2 \%$ fluoride removal efficiency, respectively at the same reaction conditions $(10 \mathrm{~g} / \mathrm{L}$ adsorbent dose). The final residual fluoride concentrations of synthetic HAp, nHAST composite and BC adsorbents were found to be $0.10,0.27$, and $0.39 \mathrm{mg} / \mathrm{L}$, respectively, being all of them below the safe limit established by the WHO. At the same adsorbent dose, if the initial fluoride concentration is higher, $10 \mathrm{mg} / \mathrm{L}$, the HAp adsorbent shows more pronounced fluoride adsorption performance (around 95.2 $\%$ ), whereas nHAST and BC perform a bit lower, about 84 and $86.6 \%$ fluoride removal. In this case, the final residual fluoride concentrations were found to be 0.48 for HAp, $1.60 \mathrm{mg} / \mathrm{L}$ for $\mathrm{nHAST}$ and $1.34 \mathrm{mg} / \mathrm{L}$ for BC. However, in all the cases the treated water meets the WHO standard for potable uses. Interestingly, the final water solution $\mathrm{pH}$ in the case of nHAST is found to be at about $\mathrm{pH} 7.5$, more suitable than both $\mathrm{BC}$ of around $\mathrm{pH} 8$ and synthetic HAp of around $\mathrm{pH}$ of 8.3. In terms of capacity, at the adsorbent dose of $10 \mathrm{~g} / \mathrm{L}$ and initial $\left[\mathrm{F}^{-}\right]=10 \mathrm{mg} / \mathrm{L}$, the stilbite/nHAp composite shows $0.84 \mathrm{mg} / \mathrm{g}$, only one point lower than the synthetic HAp $0.95 \mathrm{mg} / \mathrm{g}$ with only $9 \%$ of the weight being formed by hydroxyapatite and the advantages of more mechanical resistance offered by a $91 \%$ weight given by the zeolite. In summary, from the practical point of view, nHAST compensates the slightly less defluoridation performance by the use of locally available cheap natural raw materials as starting reagents and above all by its green synthesis procedure, in which no waste is generated even on a larger scale application. Thus, we conclude that nHAST composite is a suitable adsorbent, and has a high potential to be used as defluoridating agent in fluoride polluted drinking water. 


\subsubsection{Chromium removal from tannery wastewaters.}

Tanning process using chromium compounds is one of the most common methods for processing hides. In this process about $60-70 \%$ of chromium reacts with the hides. In other words, about $30-40 \%$ of the chromium amount remains in the solid and liquid wastes. Chromium wastewater was directly obtained from the Ethiopian directorate of Leather Industry Development Institute (LIDI) containing more than $2000 \mathrm{mg} / \mathrm{L}$ of $\mathrm{Cr}(\mathrm{III})$, much higher than the permitted limits of $2 \mathrm{ppm}$. Several methods have been used for removal of chromium from tanning wastewater: chemical reduction and precipitation, ion exchange, membrane technologies adsorption and biological methods. Adsorption and ion exchange are becoming one of the most promising methods for the removal of metal ions like $\mathrm{Cr}$ (III) from wastewater. Some of these used and developed adsorbents and ion exchangers are activated carbon, fly ash, peat, recycled alum sludge, peanut hulls, resins, biomaterials, clay materials and zeolites. In our efforts to find uses that add value to natural zeolites, we chose one of the obtained phases for $\mathrm{Cr}$ (III) removal. The zeolitic phase in this case was a rock formed by sharp needles that were identified by X-ray diffraction pattern as mixtures of Natrolite with Analcime (Figure 3). Natrolite with a unit cell formula of $\mathrm{Na}_{2} \mathrm{Al}_{2} \mathrm{Si}_{3} \mathrm{O}_{2}\left(\mathrm{H}_{2} \mathrm{O}\right)_{2}$ shows to be the main component and Analcime $\left(\mathrm{Na}\left(\mathrm{AlSi}_{2} \mathrm{O}_{6}\right)\left(\mathrm{H}_{2} \mathrm{O}\right)\right)$ which gives small XRD intensities (marked as asterisks) is the minor component. The ICP-OES analysis collected in Table 2 shows the expected $\mathrm{Si} / \mathrm{Al}$ ratio and $\mathrm{Na}$ content of Natrolite. Despite being a Na-rich zeolite, this natural zeolite (NAT) exhibited moderate $\mathrm{Cr}(\mathrm{III})$ removal efficiency (equation 3) as collected in Table 3.

$\%$ Removal of Chromium $=\frac{\mathrm{C}_{\mathrm{o}}-\mathrm{C}_{\mathrm{f}}}{\mathrm{C}_{\mathrm{o}}} \times 100 \quad$ [Equation 3] 
According to the crystallographic structure of natrolite, the Na cations are located along a screw-chain in the center of each channel. In contrast to many other zeolites the cations and water molecules are tightly held in fixed positions, which affect the cation exchange leading to a poorly efficient adsorbent for the aimed application.

Zeolite 4A is a well-known type of synthetic zeolite in the area of detergent manufacturing and water softening. Due to its large ion exchange capacity among all synthetic and natural zeolites, it is the most suitable type of zeolite for this application as ion exchanger. Structurally, zeolite $4 \mathrm{~A}$ is formed large cavities. The entrance of these cages has a diameter of $0.42 \mathrm{~nm}$ which allows different ions to diffuse easily. The large scale manufacturing of zeolite 4A uses the hydrothermal route starting from sodium silicate and sodium aluminate. Alternative routes are yet explored using cheaper raw materials including naturally available kaolin having $\mathrm{Si} / \mathrm{Al}$ ratio of 1 similar to zeolite 4A. Exploration for kaolin in Ethiopia was carried out mainly at the granites and pegmatite rocks, which have been the main sources of kaolin for the ceramic industry in Ethiopia. Among these kaolins, intensive exploration has been carried out at Bombowha and Ansho areas and both of them are related to acidic intrusive rocks. In our previous work, we optimized the synthesis parameters for the production of detergent grade zeolite 4A from the kaolin of Ethiopia [33]. In this particular case, we used the low quality type of synthetic zeolite 4A obtained using raw virgin Bombowha (Zeolite A-B) and Ansho (Zeolite A-A) kaolins prepared by the conventional hydrothermal synthesis method [34]. Table 2 collects the chemical composition of both synthetic zeolites showing high content of $\mathrm{Na}$ and $\mathrm{Si} / \mathrm{Al}$ ratio a bit higher than the expected value of 1 , due to the presence of quartz as impurity. For the $\mathrm{Cr}$ (III) removal experiments the reactor $\mathrm{pH}$ was constant at values around 4 which indicated that dealumination of the zeolite or precipitation of hydroxides could be in principle neglected. Initial removal 
values at three different adsorbent doses are collected in Table 3, as a survey for the best adsorbent. As it was mentioned earlier, the natural zeolite NAT does not show more than $50 \%$ removal of $\mathrm{Cr}$ (III) even at higher doses. The small increment from $43 \%$ at $25 \mathrm{~g} / \mathrm{L}$ to $53 \%$ at $100 \mathrm{~g} / \mathrm{L}$, is most probably due to surface exchange or other possible precipitation with the impurities of the natural zeolite. Synthetic zeolite 4A samples, with either Ansho or Bombowha kaolins, show more than $80 \% \mathrm{Cr}^{3+}$ removal at $25 \mathrm{~g} / \mathrm{L}$ and almost $100 \%$ at $100 \mathrm{~g} / \mathrm{L}$, suggesting an efficient cation exchange in this case. A more systematic study was performed using synthetic zeolite A-B since it is the lowest grade synthetic zeolite $4 \mathrm{~A}$ obtained from a mineral resource without any other industrial interest given the low quality of the final zeolite. Figure 4 shows how the adsorption efficiency (equation 4) increased with the increment in the dosage rate from $2 \mathrm{~g} / \mathrm{L}$ to $100 \mathrm{~g} / \mathrm{L}$ keeping room temperature $\left(25^{\circ} \mathrm{C}\right)$, contact time of $24 \mathrm{~h}$ and using initial chromium concentration (2036 ppm) constant. Maximum removal of $99.8 \%$ was observed with adsorbent dose of $100 \mathrm{mg} / \mathrm{L}$. However, the adsorption capacity $\left(q_{e}\right)$ decreases while increasing the adsorbent dosage, probably due to adsorption sites that remain available.

$$
q_{e}=\frac{\left(\mathrm{C}_{\mathrm{eq}}-\mathrm{C}_{\mathrm{o}}\right) \mathrm{V}}{\mathrm{m}}
$$

The adsorption capacity obtained from the graph is about $200 \mathrm{mg} / \mathrm{g}$ at the lower adsorption dose. However, the adsorption capacities for higher adsorbent doses are less than the theoretical cation exchange capacity $(95 \mathrm{mg} / \mathrm{g})$. So it is possible to say that the removal mechanism is merely due to cation exchange for these higher adsorbent doses. In summary, for this particular tannery wastewater having initial concentration of 2036 
ppm, the lowest quality type of zeolite 4A made from the low grade raw type kaolin shows a maximum removal of $99.8 \%$ reducing the concentration to $10.1 \mathrm{ppm}$ of $\mathrm{Cr}$ (III) in the final water. Using this example, attained with adsorbent dose of $100 \mathrm{~g} / \mathrm{L}$, it could possible to tune the treatment according to each factory in order to reach the EEPA limit of $2 \mathrm{ppm}$.

\subsection{Zeolitic Phases devoted to catalysis}

Two main research lines were initiated at Addis Ababa University involving zeolites as catalysts: 1) Photodegradation of dyes from textile wastewaters and 2) Conversion of glucose into of 5-HMF.

2.2.1. Photodegradation of dyes from textile wastewaters.

Manufacturing textile industry uses different dyes apart from other chemicals in their in main steps that are discharged in their wastewaters. The treatment of this wastewater requires either recycling to recover and reused the chemicals, or degradation into harmless products. In $\mathrm{TiO}_{2}$ based photocatalysis, zeolites are often used as supports either for the use of the cavities as a confined space for the synthesis of small nanoparticles, or fur the tunable chemistry of the surface that allows controlling the hydrophilicity/hydrophobicity and thus the adsorption of a particular target molecule. Very few reports are found on the use of natural zeolites. Among the zeolitic phases obtained in the geological studies of the north of the country, a phase rich in $\mathrm{Ti}$ and $\mathrm{Fe}$ could be identified. This phase was fully characterized and enriched in zeolitic phase by sonication and sedimentation [35]. The chemical composition gives with a $\mathrm{Si} / \mathrm{Al}$ molar ratio of 6.1 (Table 4) which is slightly higher than that of other natural mordenites. This difference could be due to the presence on another Si source such as Celadonite, which is also responsible of larger amounts of $\mathrm{K}, \mathrm{Mg}$ and Fe. Finally, the presence of an 
Ilmenite phase $\left(\mathrm{FeTiO}_{3}\right)$ is responsible for the high content on Ti. Figure 5 collects representative SEM micrographs of the MOR-rich natural zeolite (ET4) where crystals of Mordenite could be identified given their hexagonal morphology (Figure 5A), particles with undefined shape were identified as Celadonite (Figure 5B), and bright particles due to the higher atomic number are identified as Ilmenite (Figure 5C). The exhaustive SEM/EDX study is depicted in Figure 5D with a general EDX mapping, in which the particles richer in $\mathrm{Mg}$ could be richer in Celadonite, particles richer in Si and $\mathrm{Al}$ must correspond to MOR and there are Ilmenite particles showing a Fe and $\mathrm{Ti}$ in a ratio of 1, although the presence of $\mathrm{Ti}$ is also observed in Si-related particles. Given this composition, we tried to use this phase as a photocatalyst by several approaches: i) Simple calcination at $300,400,500$ and $600^{\circ} \mathrm{C}$ of natural zeolite ET4 aiming to form oxide phases. This method did not yield any photodegradation activity using 10ppm of methyl orange meaning that the $\mathrm{Ti}$ and Fe species are forming stable phases rather than loosely attached impurities. ii) Loading the natural zeolite with $20 \% \mathrm{TiO}_{2}$ followed by calcination at $500{ }^{\circ} \mathrm{C}$ (20TET4), and iii) Modification of the natural zeolite in order to activate the surface then loaded with $20 \% \mathrm{TiO}_{2}$ (20TET4t). The chemical composition reported in Table 4 show the same amount of $\mathrm{Ti}$ incorporated in both samples. However, the $\mathrm{TiO}_{2}$ loading procedure has led to a decrease in the content of $\mathrm{Si}$ in sample 20TET4. Further treatment of ET4 sample with $\mathrm{NH}_{4} \mathrm{Ac}+\mathrm{NH}_{4} \mathrm{~F}$ provokes further decrease with a Si/Al ratio of 2.44 . The photocatalytic activity test of 20TET4t, 20TET4 and ET4 materials is summarized in Figure 6A. The treated sample (20TET4t) shows higher activity than the one loaded without any previous treatment 20T-ET4 and ET4. However, this activity is still very low compared with other data based on synthetic zeolites [36]. Thus, we moved to synthetic zeolites where we applied the same surface modification methods obtaining remarkable differences. Zeolite Y (Zeolyst code 
CVB400, called ZY5 here) was treated using $\mathrm{NH}_{4} \mathrm{Ac}+\mathrm{NH}_{4} \mathrm{~F}$, leading to selective dealumination of the surface, then loaded with $\mathrm{TiO}_{2}$ (20TZY5t) yielding a final photocatalyst [37]. Upon treatment, the zeolite framework remains intact, but $50 \%$ of the $\mathrm{Al}$ atoms were removed from the surface of the zeolite (Table 5). Figure 6B plots the degradation percentage versus time of the treated sample (20TZY5t) and compared with the $\mathrm{TiO}_{2}$ loaded in a parent zeolite $\mathrm{Y}(20 \mathrm{TZY} 5)$, and pristine $\mathrm{TiO}_{2}$. Table 5 also collects relevant data including chemical composition and catalytic results. At 90 min of UV light irradiation, the $\mathrm{TiO}_{2}$ loaded treated sample (20TZY5t) degrades $92 \%$ of 10 ppm methyl orange (MO), while the one supported on the parent zeolite (20TZY5) converted only $7.6 \%$. The mass normalized turnover rate $\left(\mathrm{TOR}_{\mathrm{m}}\right)$ of the treated zeolite loaded with $\mathrm{TiO}_{2}$ was $226.4 \mu \mathrm{mol} \mathrm{g} \mathrm{g}^{-1}$, about 12 times higher than that of the parent zeolite loaded with the same amount of $\mathrm{TiO}_{2}\left(18.7 \mu \mathrm{mol} \mathrm{g} \mathrm{g}^{-1} \mathrm{~h}^{-1}\right)$. The reusability test of these photocatalysts showed negligible leaching of $\mathrm{Ti}^{4+}$ species during the photocatalytic reaction. The better photocatalytic performance and preventing of leaching of the $\mathrm{TiO}_{2}$ supported on treated zeolite could be due to a more efficient interaction of the $\mathrm{TiO}_{2}$ with the zeolite surface leading to higher adsorption capacity. Finally, a systematic study using zeolites as supports of $\mathrm{TiO}_{2}$ allowed us treating real waters from the textile industry of Ethiopia with promising yields [36]. Zeolite Y with $\mathrm{SiO}_{2} / \mathrm{Al}_{2} \mathrm{O}_{3}$ ratio of 60 (Zeolyst code $\mathrm{CBV} 760$, called ZY60 here) loaded with 10 and $40 \% \mathrm{TiO}_{2}$ gave the highest $\mathrm{TOR}_{\mathrm{m}}$ in the degradation of the model pollutant (MO) (Table 5). The $\mathrm{TOR}_{\mathrm{m}}$ increased as the loading decreased from 40 to $10 \%$ indicating that the specific photocatalytic activity is enhanced reaching our optimum catalyst when loading ratio decreased. Furthermore, reusability of the best catalysts in three cycles allowed concluding that the zeolite is preventing leaching of $\mathrm{TiO}_{2}$ nanoparticles adding value to the role of zeolites in enhancing photocatalytic activity. The real wastewater 
includes not only mixture of organic dyes but also other chemicals from the bleaching steps; therefore in this case it is not possible to obtain neither accurate concentrations nor turnover number of the degradation reaction. The quantification was based on the ratio $A_{t} / A_{o} \times 100$; where $A_{t}$ is absorbance at time $t$ and $A_{o}$ is the initial absorbance. Figure 7 plots the photodegradation percentage of dyes in the real wastewater sample using the optimized $\mathrm{TiO}_{2}$ /zeolite $\mathrm{Y}\left(\mathrm{CBV} 760\right.$, called $\mathrm{ZY} 60$ ) catalyst with different $\mathrm{TiO}_{2}$ loadings. The photocatalytic degradation in the real wastewater reached $83 \%$ and $87 \%$ after 9 hours of reaction time with the 10TZY60 and 40TZY60, respectively. The supported $\mathrm{TiO}_{2} /$ Zeolite $\mathrm{Y}$ photocatalyst behaved better than pure $\mathrm{TiO}_{2}(69 \%)$ despite the weight $\%$ of $\mathrm{TiO}_{2}$ in the composites is lower. Besides, in the real case, adsorption plays a big role. If we take the absorbance value at the dashed line in Figure 7, 41\%, 56\% and $28 \%$ of total absorbance disappears at 0 h, i.e., after putting the real sample in contact with 10TZY60, 40TZY60 and $\mathrm{TiO}_{2}$ catalysts, without UV radiation. If we take these values as the initial absorbance and account for the total degradation performance at $9 \mathrm{~h}$, the actual degradation capacity of 10TZY60 increases (42\%) versus the hybrid photocatalyst 40TZY60 (30\%). This calculation may tentatively lead to conclude that the best performance is obtained when $10 \% \mathrm{TiO}_{2}$ is loaded in Zeolite Y CBV760. In this particular case, the Total Organic Carbon of the real water was reduced in the best case up to $84 \%$ (Table 5). Final studies imply the use of semi-amorphous $\mathrm{TiO}_{2}$ avoiding calcination steps; this work is still in progress [38].

\subsubsection{Conversion of glucose into of 5-HMF}

One of the most investigated renewable building blocks in recent years is 5hydroxymethylfurfural (5-HMF), given its versatility and potential availability from carbohydrates. In the course of our work, we tested several synthetic, natural and 
modified zeolites in the conversion of glucose to 5-HMF using ionic liquid and biphasic system (water-acetone/ethylacetate) as solvents. Initially, another natural zeolitic obtained in the north of Ethiopia mainly formed by mordenite was tested as acid catalyst for the dehydration of glucose to 5-HMF. This MOR-rich phase was contaminated by quartz and ilmenite, thus mechanical separation processes were applied to obtain a richer MOR phase [39]. This mixture was separated using ultrasonic suspension and separation. Ilmenite is $\mathrm{FeTiO}_{3}$ and quartz is silica, these two phases are denser than mordenite and therefore it was expected that during sonication, the mordenite less dense particles remained in the suspension. The suspension was then decanted and filtered out; it was also dried and calcined at $500{ }^{\circ} \mathrm{C}$ to yield the natural MOR-rich sample. The separated mixture shows two clearly different X-ray patterns, as depicted in Figure 8, one is mainly mordenite and the other mainly quartz and ilmenite with a yield of about $45-50 \%$ mordenite. Later on, modification processes as those described above, were applied to further obtain the desired acidity for this reaction which implies a combination of Lewis and Brönsted sites. Along with the modification processes of the natural enriched MOR, parallel experiments were carried out with synthetic mordenite (Zeolyst code CBV21A Si/Al = 10.5) [40]. Mordenite consists of pore channels of $0.67 \times 0.70 \mathrm{~nm}$ interconnected by smaller pores of $0.34 \times 0.48 \mathrm{~nm}$. Given the small-medium dimensions of its pores, diffusion limitations are usually enhanced by the generation of mesoporosity accompanying dealumination processes. Commercial mordenite (CBV21A) with $\mathrm{Si} / \mathrm{Al}$ of 10.5 , and natural mordenite from Ethiopia $(\mathrm{Si} / \mathrm{Al}=6.2)$ have been treated under mild conditions $(\mathrm{pH}=6)$ in order to maintain high crystallinity in the final zeolites. Table 6 shows the sample codes along with each particular treatment. Previous experiments using this mild treatments show the creation of small mesoporosity in MOR and selective surface $\mathrm{Si} / \mathrm{Al}$ modifications 
without losing crystallinity. The $\mathrm{NH}_{4} \mathrm{Ac}$ acts as a chelating agent of the surface aluminum and the $\mathrm{NH}_{4} \mathrm{~F}$ step helps in washing off the silicon that remains weakly bonded to the framework of the zeolite, by forming hexafluorosilicate. As a consequence, only slight change in the $\mathrm{Si} / \mathrm{Al}$ ratio is expected. After treatment, the modified mordenite was calcined at $500{ }^{\circ} \mathrm{C}$ for $6 \mathrm{~h}$ in order to obtain the acid form. The impact of this treatment is noticeable in the synthetic mordenite, showing certain degree of mesoporosity and varying the surface hydrophilicity while maintaining the bulk Si/Al ratio and crystallinity of the sample [40]. In natural mordenite, small mesoporosity is created, showing strong increase in crystallinity most probably due to the dissolution of extra framework amorphous species [39]. For example, in the case of natural MOR, sample NM-M1, with the two steps treatment, TEM images (Figure 9) show the typical mordenite structure along with some mesoporosity within the particle. However, the natural zeolite comprise significant amount of iron embedded naturally in the crystals that hindered the use as catalysts. In the case of synthetic mordenites, the resulting improved acidity and porosity of these systems showed certain impact in the catalytic behavior in different media. Modified mordenites were used in the direct conversion of glucose into 5-hydroxymethylfurfural (5-HMF) in two different media: ionic liquid 1butyl-3-methylimidazolium bromide ([BMIM]Br) and a biphasic system composed of water-acetone and ethyl acetate [40]. The impact of the modification treatments in the final catalytic performances is different in the two synthesis media tested (Figure 10). Modified mordenite with a moderate $\mathrm{Si} / \mathrm{Al}$ ratio of 11.2 and a high content of strong Brönsted acid sites $\left(\mathrm{TPD}_{\mathrm{NH} 3}\right.$ acidity of $1.39 \mathrm{mmol} / \mathrm{g}$ ), treated with $1 \mathrm{M} \mathrm{NH} 4 \mathrm{Cl}$ only, show the highest catalytic activity in the presence of ionic liquid, 64\% 5-HMF yield and 97\% glucose conversion. The mordenite with total acidity of $1.51 \mathrm{mmol} / \mathrm{g}$, mainly due to Lewis sites, treated with $1 \mathrm{M} \mathrm{NH} \mathrm{NH}_{4} \mathrm{Cl}$ and $2.4 \mathrm{M} \mathrm{NH} 4 \mathrm{~F}$, gave the best results in biphasic 
media, 50\% 5-HMF yield and 98\% conversion. In summary, the presence of strong Lewis acidity has a major effect on catalytic activity in aqueous-organic biphasic medium. In contrast, the quick adsorption and strong interaction of the ionic liquid with the zeolite, most probably hinders the diffusion of the products, enhancing the role of zeolite mesoporosity on the catalytic activity when the reaction is carried out in ionic liquid solution [41, 42].

\section{Conclusions}

Natural zeolite, stilbite, from Ethiopia has been successfully used to grow nanocrystals of hydroxyapatite resulting in an excellent performance in defluoridation of drinking waters. The synthesis is done using only a phosphate source, at autogenous $\mathrm{pH}$ and room temperature. The defluoridation capacity is comparable to that of Bone Char and a synthetic hydroxyapatite except that the composite contains only $9 \%$ of active phase. As a result, there is a product in the market based on a natural zeolite from Ethiopia. As a long term development, we are working in a new scale up project aiming to study the feasibility of the synthesis of zeolite 4A based on virgin kaolin from Ethiopia for wastewater treatment. New studies are being initiated using zeolites (synthetic) as supports for photocatalysis, given the efforts of Ethiopia in using solar energy, thus I believe that new relevant results will come in this area. Finally, the fine tuning of synthetic zeolites, with emphasis in surface modifications, may allow for improvements in catalytic processes involving green chemistry. We may conclude that our efforts in bringing scientific knowledge related to zeolites to Ethiopia have been so far successful.

\section{Acknowledgments}


ID is grateful to CSIC for her research leave at AAU and HU. The Spanish Research Council CSIC I-COOP+-2014 (COOPB20082) is acknowledged for funding. This work has been (partially) funded by the Spanish State Research Agency (AEI) and the European Regional Development Fund (FEDER) through the Project MAT2016-77496R (AEI/FEDER, UE). Special thanks go to the members of the Molecular Sieves Group at ICP-CSIC. Finally my deepest appreciation goes to Wondimagenge Mamo, Taju Sani, Kiros Guesh, Lijalem Ayele and Yaregal Awoke.

\section{References}

[1] Zeolites in Industrial Separation and Catalysis. Edited by Santi Kulprathipanja Wiley-VCH, Weinheim, Germany, 2010.

[2] T. Rango, A. Vengosh, M. Jeuland, R. Tekle-Haimanot, E. Weinthal, J. Kravchenko, C. Paul, P. McCornick, Sci. Total Environ. 496 (2014) 188-197.

[3] J. Fawell, K. Bailey, J. Chilton, E. Dahi, L. Fewtrell, Y. Magara, Fluoride in Drinking water, World Health Organisation, IWA Publishing, London 2006.

[4] H. Kloos, R.T. Haimanot, Trop. Med. Int. Health 4 (1999) 355-364.

[5] UNIDO project number: TE/ETH/08/008 Technical assistance project for the upgrading of the Ethiopian leather and leather products industry. Vienna, 2012.

[6] A. A. Belay. J. Environ. Protect . 01 (2010) 53-58.

[7] M. D. Roldan, R. Blasco, F. J. Caballero, F. Castillo, Arch. Microbiol. 169 (1998) $36-42$

[8] P. Van Straaten, Ethiopia in Rocks for Crops: Agrominerals of Sub-Saharan Africa, ICRAF, Nairobi, 2002, pp 137-144. ISBN 0889555125, 9780889555129.

[9] Report on Exploration and Evaluation of Zeolite at Hawassa Area, SNNP Regional State by M.Tigistu, T. Negash, and L. Kassa Addis Ababa, July 2001. 
[10] S. Mehretie, J. Losada, M. Tessema, S. Admassie, T. Solomon, J. Pérez-Pariente, I. Díaz, Analyst 137 (2012) 5625-5631.

[11]S. L. Hailu, B. U. Nair, A. Rathinam, M. Redi-Abshiro, R. Aravindhan, I. Diaz, M. Tessema, J. Porous Mater. 22 (5) (2015) 1363-1373.

[12] S. L. Hailu, B. U. Nair, M. Redi-Abshiro, R. Aravindhan, I. Diaz, M. Tessema RSC Adv. 5 (2015) 88636-88645.

[13] S. L. Hailu, B. U. Nair, M. Redi-Abshiro, I. Diaz, R. Aravindhan, M. Tessema Chin. J. Catal. 37 (2016) 135-145.

[14]T. Desalegn, I. J. Villar-Garcia, P. Licence, I. Díaz, Y. Chebude Starch/Stärke 66 (2014) 385-392.

[15]N. Getachew, Y. Chebude, M. Sánchez-Sánchez, I. Diaz, J. Porous Mater. 21 (2014) 769-773.

[16] M. Sánchez-Sánchez, N. Getachew, K. Díaz, M. Díaz-García, Y. Chebude, I. Diaz, Green Chem. 17 (2015) 1500-1509.

[17]K. Guesh, C. Alves, M. Diaz-Garcia, I. Diaz, A. Mayoral, M. Sanchez-Sanchez, submitted to Cryst. Growth Design

[18]L. Gómez-Hortigüela, J. Pérez-Pariente, R. García, Y. Chebude, I. Díaz, Sep. Purif. Technol. 120 (2013), 224-229.

[19]W. Mamo, G. Woldentinsae, J. L. Costafreda Mustelier, D. Martín Sánchez, I. Díaz. IV Congreso Nacional de Áridos, Madrid 2015 pp 500-508.

[20]M. Dessalegne, F. Zewge, W. Mammo, G. Woldetinsae, I. Diaz, submitted to Bull. Chem. Soc. Ethiop.

[21]L. Ayele, E. Perez, W. Mammo, G. Woldetinsae, I. Diaz, to be submitted to Bull. Chem. Soc. Ethiop. 
[22]L. Ayele, J. Pérez-Pariente, Y. Chebude, I. Díaz, New J. Chem. 40 (2016) 34403446.

[23]L. Ayele, J. Perez Pariente, Y. Chebude, I. Díaz, Appl. Clay Sci. 132-133 (2016) $485-490$.

[24]UNICEF's Position on Water Fluoridation:

http://www.nofluoride.com/Unicef_fluor.cfm consulted on march 31, (2014).

[25] M. Dessalegne, F. Zewge, N. Pfenninger, C. A. Johnson, I. Diaz, Water Air Soil Pollut. 227:381 (2016) 1-13.

[26]T. Sani, M. Adem, G. Fetter, P. Bosch, I. Diaz, Water Air Soil Pollut. 227:90 (2016) $1-8$

[27]M. Adem, T. Sani, Y. Chebude, G. Fetter, P. Bosch, I. Diaz, Bull. Chem. Soc. Ethiop. 29 (2015) 53-62.

[28] M. Dessalegne, F. Zewge, I. Diaz J. Chem. Technol. Biotechnol (2016) DOI: 10.1002/jctb.5041.

[29]L. Gómez-Hortigüela, A. B. Pinar, J. Pérez-Pariente, Y. Chebude, I. Díaz Microporous Mesoporous Mater, 193 (2014) 93-102.

[30]L. Gómez-Hortigüela, J. Pérez-Pariente, Y. Chebude, I. Díaz, RSC Adv. 4 (2014) 7998-8003.

[31]T. Sani, L. Gómez-Hortigüela, Y. Chebude, J. Pérez-Pariente, I. Díaz, submitted to Micoporous Mesoporous Mater.

[32]T. Sani, L. Gómez-Hortigüela, J. Pérez-Pariente, Y. Chebude, I. Díaz, Sep. Purif. Technol. 157 (2016) 241-248.

[33]L. Ayele, J. Pérez-Pariente, Y. Chebude, I. Díaz, Microporous Mesoporous Mater 215 (2015) 28-35. 
[34]L. Ayele, E. Perez, A. Mayoral, Y. Chebude, I. Diaz, submitted to J. Chem. Tech. Biotech.

[35]K. Guesh, M. J. López-Muñoz, C. Márquez-Álvarez, Y. Chebude, I. Díaz, Bull. Chem. Soc. Ethiop. 29(3) (2015) 431-440.

[36]K. Guesh, A. Mayoral, C. Márquez-Álvarez, Y. Chebude, I. Díaz, Microporous Mesoporous Mater. 225 (2016) 88-97.

[37]K. Guesh, C. Márquez-Álvarez, Y. Chebude, I. Díaz. Appl. Surf. Sci. 378 (2016) 473-478.

[38]K. Guesh, J. López-Muñoz, C. Márquez-Álvarez, Y. Chebude, I. Díaz. Manuscript under preparation.

[39] W. Mamo, Y. Awoke, Y. Chebude, I. Díaz, Bull. Chem. Soc. Ethiop. 29 (1) (2015) 95-103.

[40]W. Mamo, Y. Chebude, C. Márquez-Álvarez, I. Diaz, E. Sastre, Catal. Sci. Technol. 6 (2016) 2766-2774.

[41] Y. Chanie, I. Díaz, E. Pérez, J. Chem. Technol. Biotechnol. 91 (2016) 705-710.

[42]L. Ayele, G. Dadi, W. Mamo, Y. Chebude, I. Díaz, Bull. Chem. Soc. Ethiop. 28 (2014) $1-8$. 
Table 1. Elemental analyses of the zeolite precursor (STI) and the stilbite/nanoHydroxyapatite composite adapted from reference 32 .

\begin{tabular}{ccccccc}
\hline \multirow{2}{*}{ Samples } & \multicolumn{7}{c}{ Element $(w t$ \%) } & HAp wt \% \\
& Al & Si & Na & Ca & P & \\
\hline STI & 8.0 & 20.4 & 0.5 & 4.9 & - & - \\
Stilbite/nHAp & 7.5 & 18.2 & 0.2 & 5.3 & 1.7 & 9.2 \\
\hline
\end{tabular}


Table 2. Elemental analyses of the natural and synthetic zeolites. Adapted from reference 34.

\begin{tabular}{ccccccc}
\hline \multirow{2}{*}{ Samples } & \multicolumn{7}{c}{ Element (wt \%) } \\
& Si & Al & Na & Ca & Mg & Si/Al \\
& & & & & & \\
\hline NAT & 25.6 & 13.1 & 10.6 & 0.4 & 0.1 & 1.9 \\
Zeolite A-A & 15.8 & 14.0 & 11.4 & 0.0 & 0.0 & 1.1 \\
Zeolite A-B & 13.8 & 12.7 & 11.5 & 0.0 & 0.0 & 1.1 \\
\hline
\end{tabular}


Table 3. $\mathrm{Cr}(\mathrm{III})$ removal (\%) from tannery wastewater using different adsorbents. Adapted from reference 34 .

\begin{tabular}{cccc}
\hline \multirow{2}{*}{ Adsorbents } & \multicolumn{3}{c}{ Dosage rate (g/L) } \\
& $\mathbf{2 5}$ & $\mathbf{5 0}$ & $\mathbf{1 0 0}$ \\
\hline NAT & 43.5 & 50.4 & 53.5 \\
Zeolite A-A & 84.9 & 92.0 & 99.8 \\
Zeolite A-B & 87.0 & 94.0 & 99.6 \\
\hline
\end{tabular}


Table 4. ICP Elemental Analysis of natural zeolites used to prepare photocatalysts: natural zeolite ET4 untreated, loaded with $20 \% \mathrm{TiO}_{2}$ (20TET4) and previously treated and further loaded (20TET4t). Adapted from reference 35.

\begin{tabular}{ccccccccc}
\hline Samples & & \multicolumn{8}{c}{ Element (wt \%) } \\
& Si & Al & Na & K & Ca & Mg & Fe & Ti \\
& & & & & & & & \\
\hline ET4 & 22.9 & 3.6 & 1.3 & 3.6 & 1.8 & 1.1 & 10.2 & 3.5 \\
20TET4 & 19.8 & 5.6 & 1.3 & 3.5 & 2.8 & 1.5 & 9.9 & 17.5 \\
20TET4t & 20.9 & 8.2 & 1.4 & 3.8 & 2.9 & 1.7 & 9.8 & 17.0 \\
\hline
\end{tabular}


Table 5. ICP Elemental Analysis and catalytic results of the photocatalysts prepared based on synthetic zeolites CBV400 (ZY5) and CBV760 (ZY60). Adapted from reference 36 and 37.

\begin{tabular}{cccccc}
\hline Sample & Si/Al ratio & $\begin{array}{c}\mathbf{T i O}_{\mathbf{2}} \\
(\% \mathbf{w t})\end{array}$ & $\begin{array}{c}\% \mathbf{M O} \\
\mathbf{d e g}^{\mathbf{a}}\end{array}$ & $\begin{array}{c}\mathbf{T O R}_{\mathbf{m}} \\
\left(\mu \mathbf{m o l ~ g}^{-\mathbf{1}} \mathbf{h}^{\mathbf{- 1}}\right)\end{array}$ & $\begin{array}{c}\mathbf{T O C} \\
(\mathbf{m g} / \mathbf{L})\end{array}$ \\
\hline 20TZY5 & 2.6 & 9.9 & 7.6 & 18.7 & - \\
20TZY5t & 4.8 & 10.5 & 92.0 & 226.4 & - \\
10TZY60 & 30 & 8.5 & 61.2 & 526.0 & 5.6 \\
40TZY60 & 30 & 30.1 & 87.2 & 177.1 & 8.2 \\
$\mathrm{TiO}_{2}$ & - & 100 & 43 & 26.3 & 17.3 \\
\hline
\end{tabular}

a) photocatalytic degradation after $90 \mathrm{~min}$ UV irradiation for ZY5 and $60 \mathrm{~min}$ UV radiation for ZY60 and $\mathrm{TiO}_{2}$. b) TOC: Total Organic Carbon in the real wastewater before reaction was $34.2 \mathrm{mg} / \mathrm{L}$. 
Table 6. Chemical analyses (ICP) and degree of crystallinity $\left(\mathrm{C}_{\mathrm{XRD}}\right)$ of the synthetic (S) and natural $(\mathrm{N})$ modified mordenites. Adapted from reference 40.

\begin{tabular}{c|ccc|ccc}
\hline Treatment & Sample & Si/Al & $\mathbf{C}_{\text {XRd }}(\%)$ & Sample & Si/Al & C $_{\text {XRD }}(\%)$ \\
\hline PARENT & SMOR & 10.5 & 100 & NMOR & 6.2 & 100 \\
$3 \mathrm{M} \mathrm{NH}{ }_{4} \mathrm{Ac}+$ & SM-M1 & 11.5 & 88 & NM-M1 & 6.4 & 199 \\
$2.4 \mathrm{M} \mathrm{NH}_{4} \mathrm{~F}$ & & & & & & \\
$3 \mathrm{M} \mathrm{NH}_{4} \mathrm{Ac}$ & SM-M2 & 11.4 & 63 & NM-M2 & 6.5 & 203 \\
$3 \mathrm{M} \mathrm{NH}_{4} \mathrm{Cl}$ & SM-M3 & 11.2 & 118 & NM-M3 & 6.2 & 177 \\
$1 \mathrm{M} \mathrm{NH}_{4} \mathrm{Ac}$ & SM-M4 & 11.1 & 57 & NM-M4 & 6.1 & 193 \\
$1 \mathrm{M} \mathrm{NH}_{4} \mathrm{Cl}$ & SM-M5 & 11.1 & 84 & NM-M5 & - & 189 \\
$1 \mathrm{M} \mathrm{NH}_{4} \mathrm{Ac}+$ & SM-M6 & 11.7 & 55 & NM-M6 & 6.4 & 190 \\
$2.4 \mathrm{M} \mathrm{NH}_{4} \mathrm{~F}$ & & & & & & \\
$3 \mathrm{M} \mathrm{NH}_{4} \mathrm{Cl}+2.4$ & SM-M7 & 12.5 & 52 & NM-M7 & 6.6 & 93 \\
$\mathrm{M} \mathrm{NH}_{4} \mathrm{~F}$ & & & & & & \\
$1 \mathrm{M} \mathrm{NH}_{4} \mathrm{Cl}+2.4$ & SM-M8 & 11.4 & 94 & NM-M8 & 6.6 & 104 \\
$\mathrm{M} \mathrm{NH}_{4} \mathrm{~F}$ & & & & & \\
\hline
\end{tabular}


Figure 1. a) Low-magnification TEM image of stilbite/nHAp composite. b) EELS spectra of the region marked in c). c) Low-magnification STEM/HAADF/EELS results of stilbite/nHAp composite where the spectrum imaging was performed (green rectangle) showing chemical map extracted from the $\mathrm{Si}$ (green) and $\mathrm{Ca}$ (red) signals.
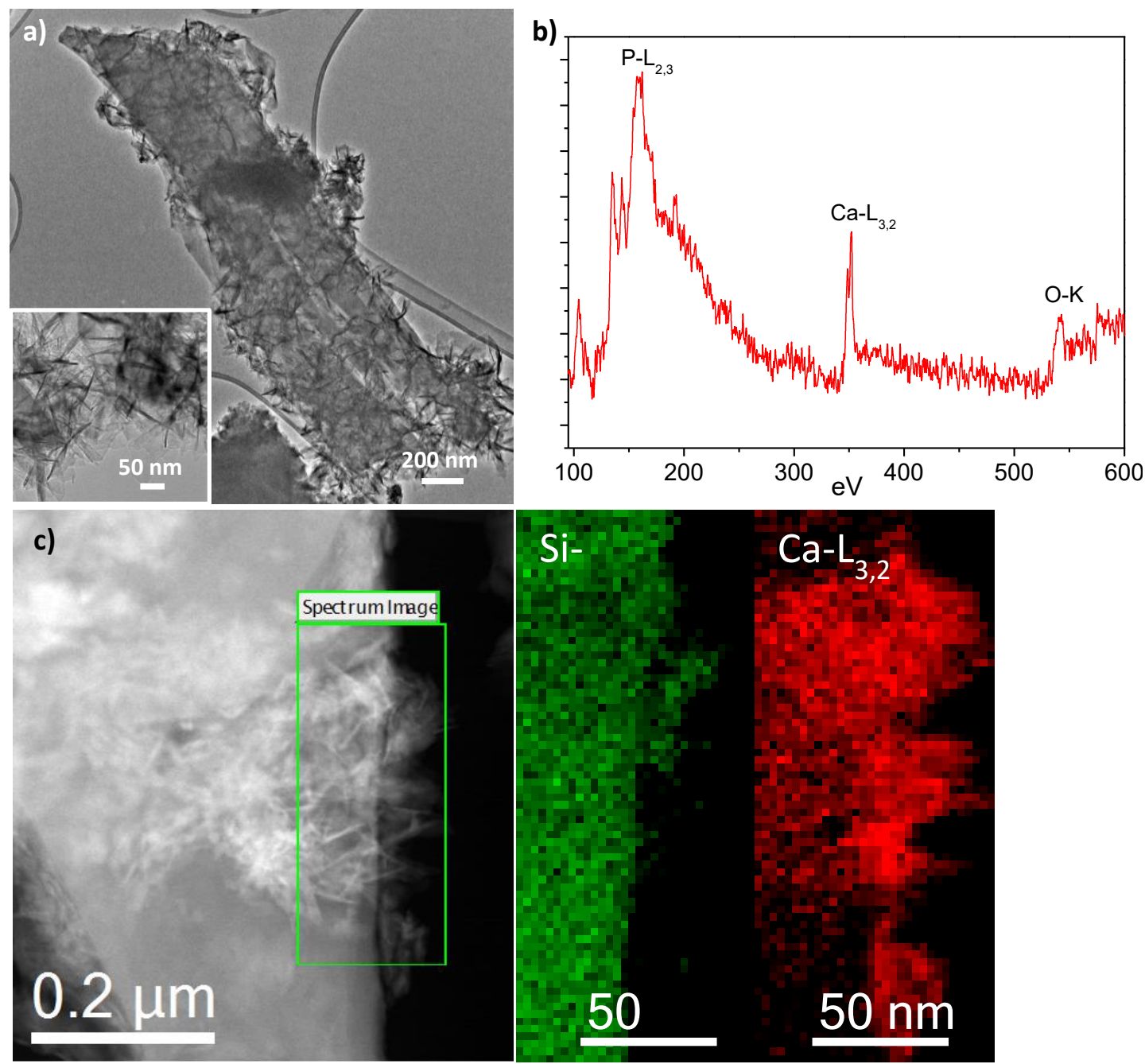
Figure 2. Fluoride removal efficiency (\%) of BC, synthetic HAp, and stilbite /nanoHAp (nHAST) composite samples at $10 \mathrm{~g} / \mathrm{L}$ of adsorbent dose at two different initial concentrations.

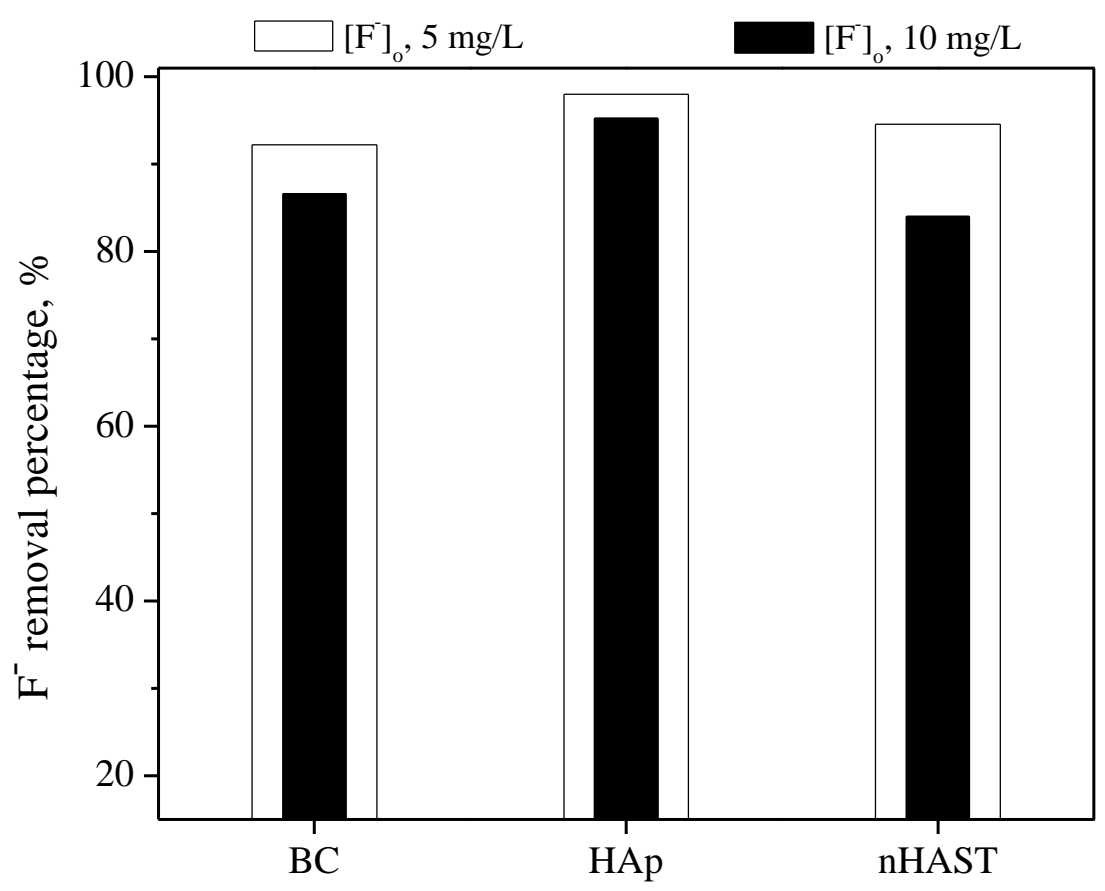


Figure 3. X ray diffraction pattern of a natural zeolite formed mainly by Natrolite (NAT) with a small presence of Analcime (*).

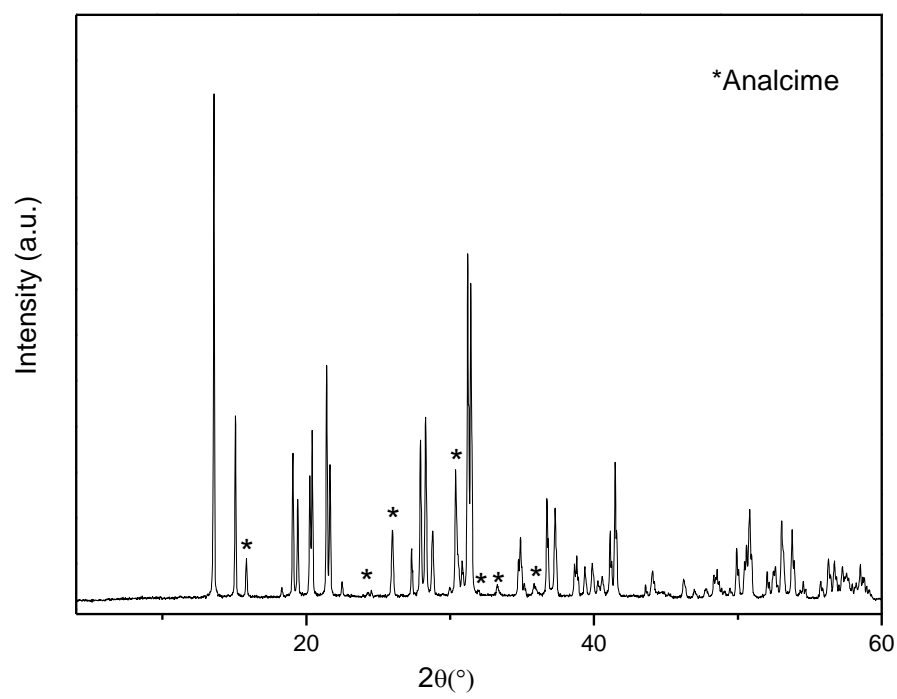


Figure 4. $\mathrm{Cr}$ (III) removal from tannery wastewaters using synthetic zeolite A-B. (O): \% Removal, (ם): Adsorption capacity, $q_{e}$. Adapted from reference 34.

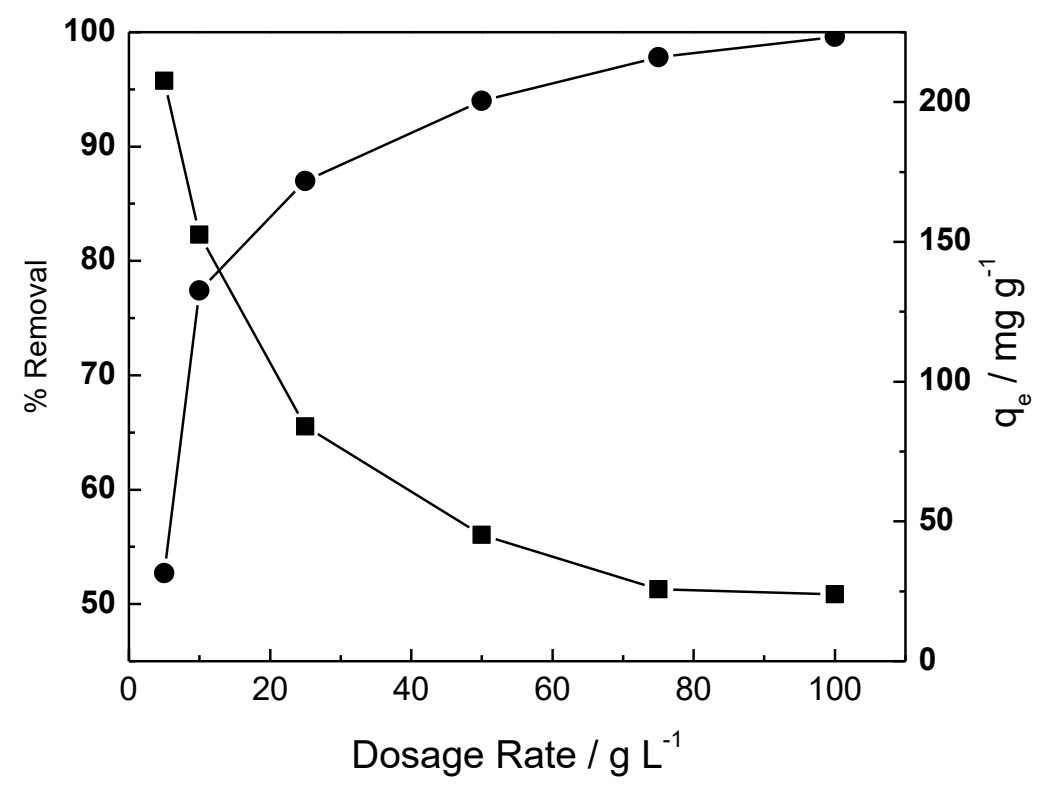


Figure 5. SEM micrographs of sample ET4 showing A) Mordenite, B) Celadonite and C) Ilmenite. D) SEM/EDX Mapping. Printed with the permission of Bulletin of the Chemical Society of Ethiopia.
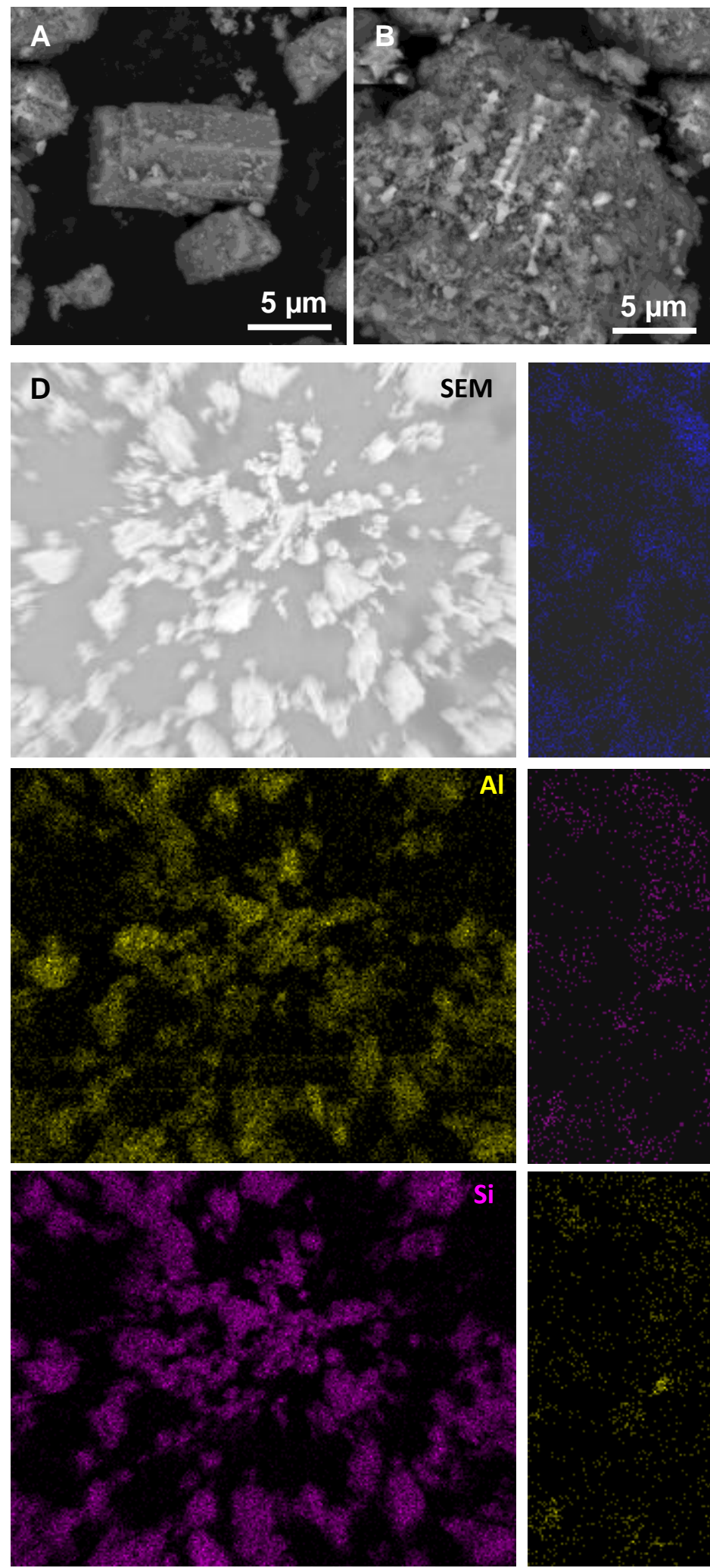

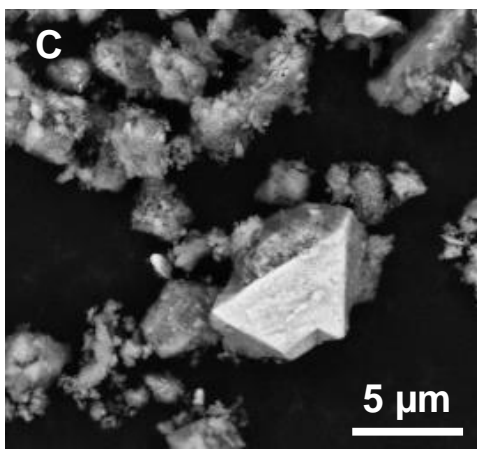

$\mathrm{Mg}$

$\mathrm{Fe}$
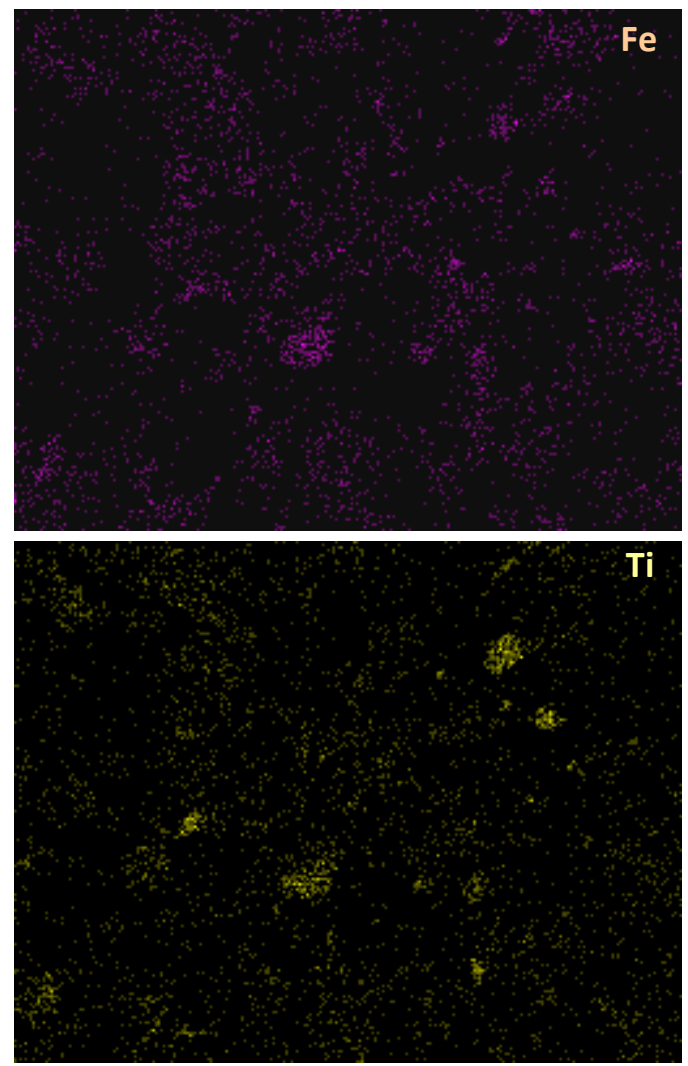
Figure 6. Photocatalytic degradation of $10 \mathrm{ppm}$ MO using (A) natural zeolites and modified synthetic zeolite $\mathrm{Y}$ (B). The dashed line indicates the starting of UV irradiation. Modified from references 35 and 37.
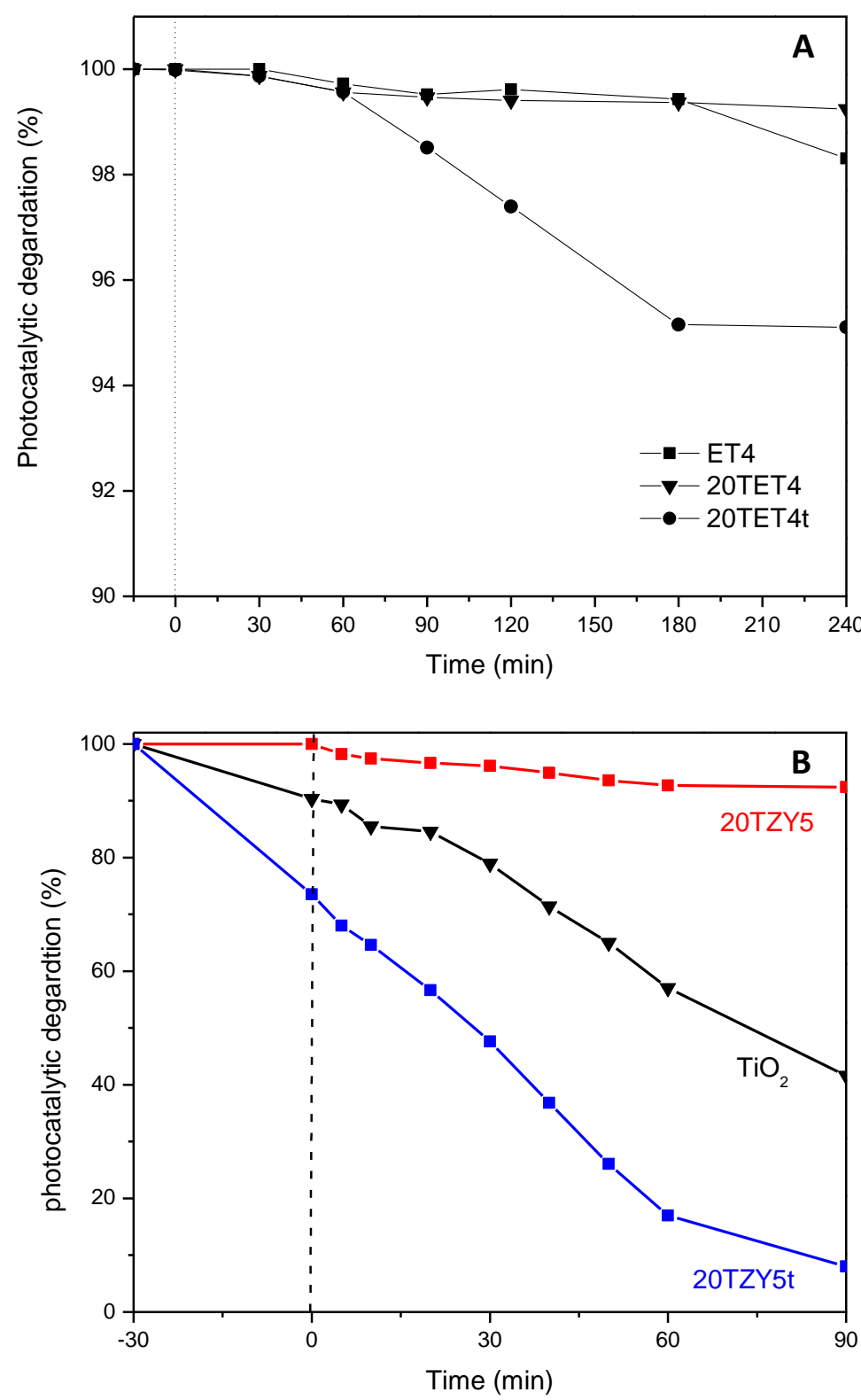
Figure 7. Photocatalytic degradation of real textile wastewater using 10TZY60, 40TZY60 and $\mathrm{TiO}_{2}$. Reproduced from reference 36 by permission of Elsevier.

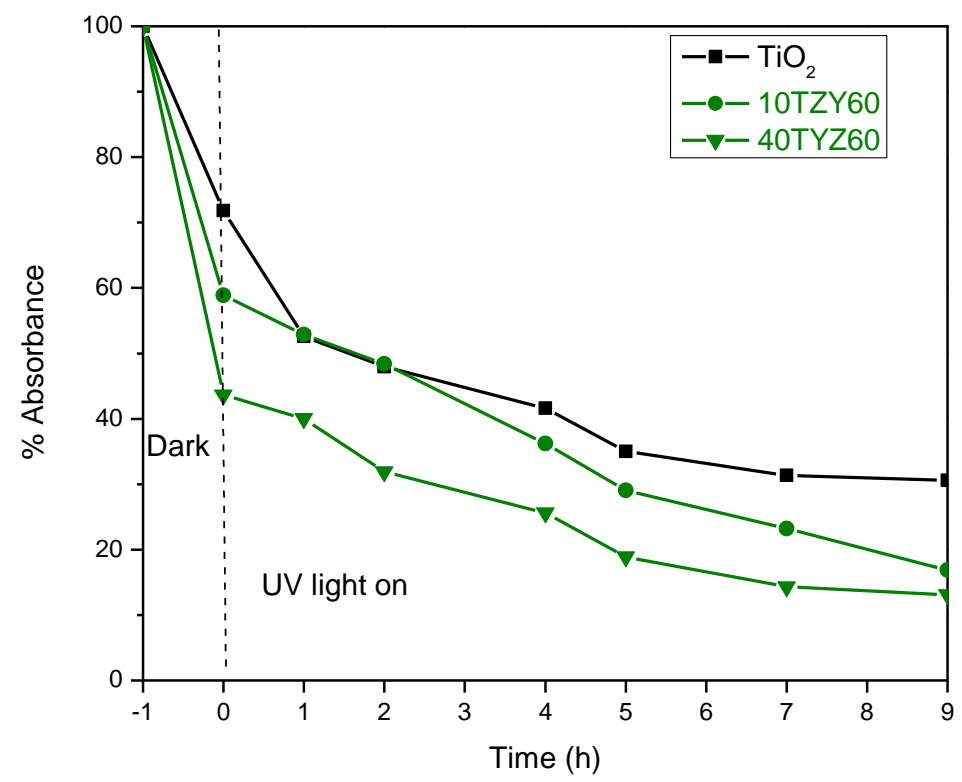


Figure 8. X ray diffraction pattern of raw MOR-zeolitic phase with impurities of quartz (Q) and Ilmenite (I). Blue profile correspond to the MOR-enriched phase after separation.

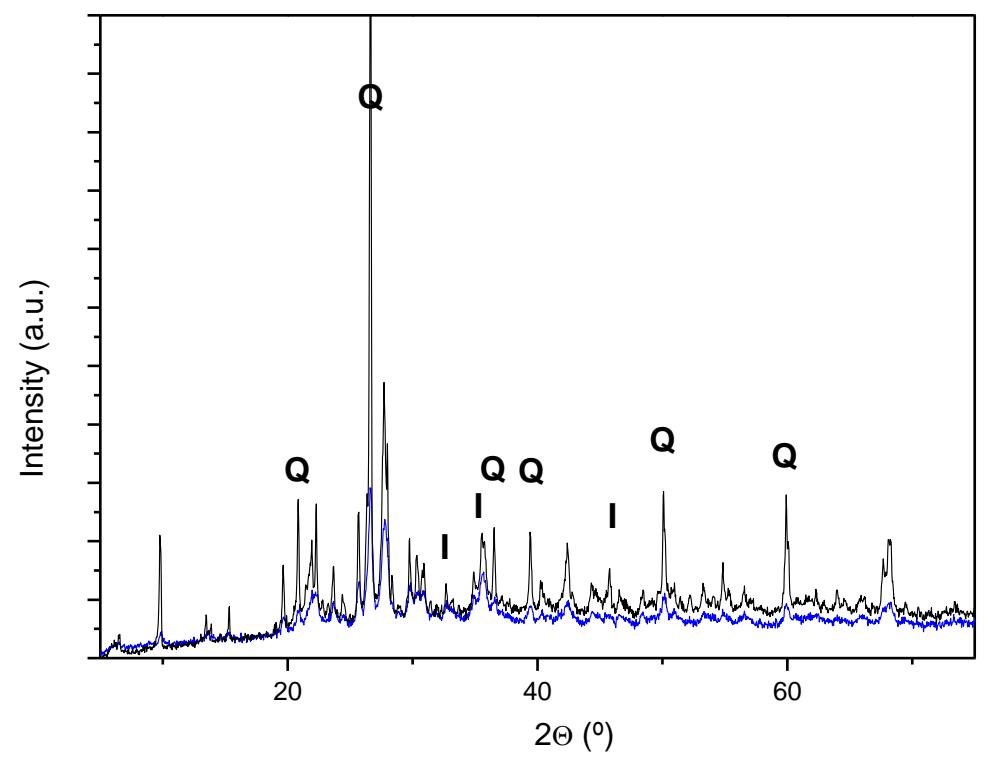


Figure 9. TEM images of NM-M1 at different magnifications. Adapted from reference 39.
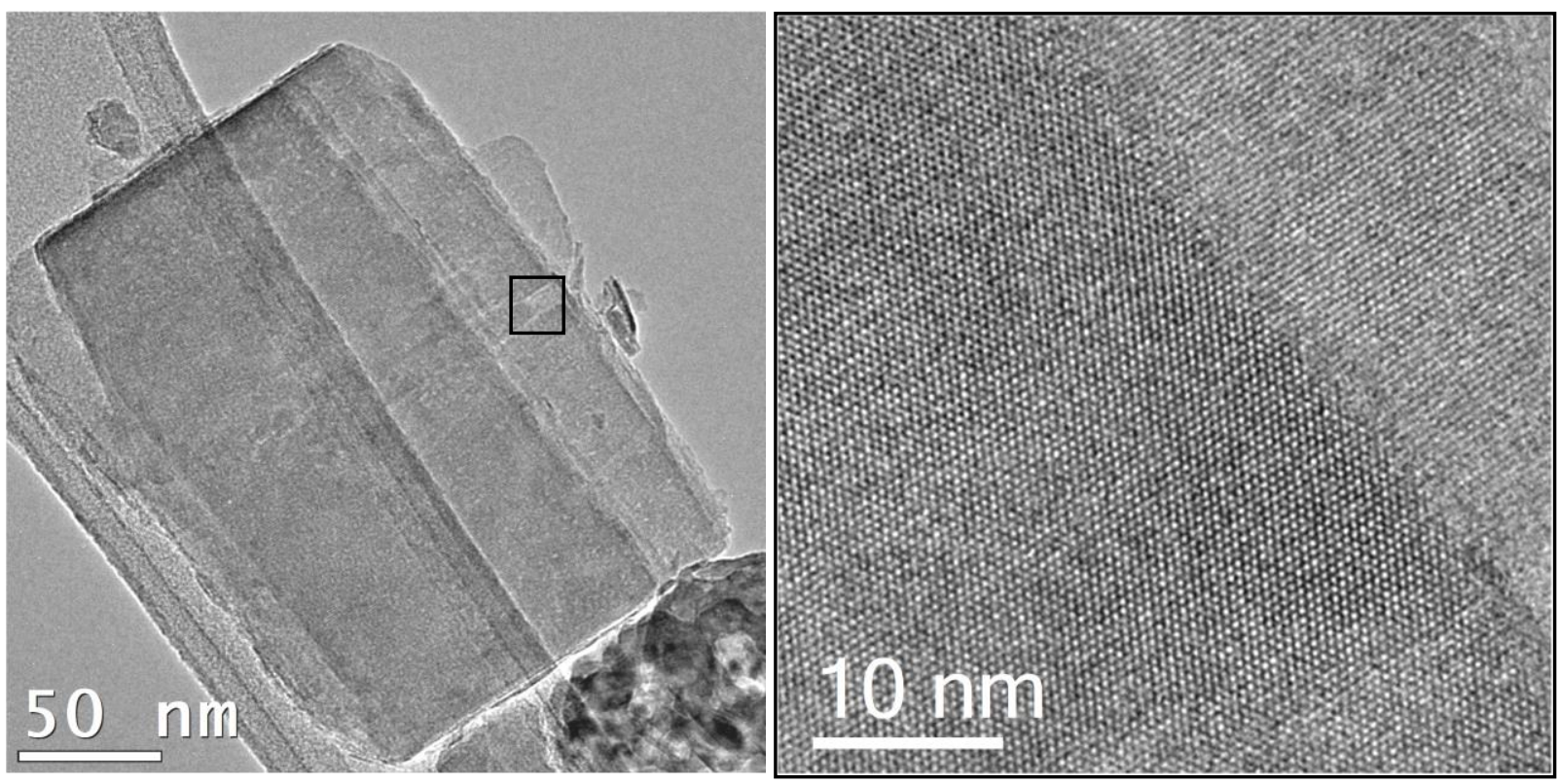
Figure 10. Comparison of the performance of the different modified Synthetic Mordenites (SM samples) in both systems: in IL at $100^{\circ} \mathrm{C}$ and $6 \mathrm{~h}$ (dark grey) and biphasic at $65^{\circ} \mathrm{C}$ and $9 \mathrm{~h}$ (light grey). Reproduced from reference 40 by permission of The Royal Society of Chemistry.

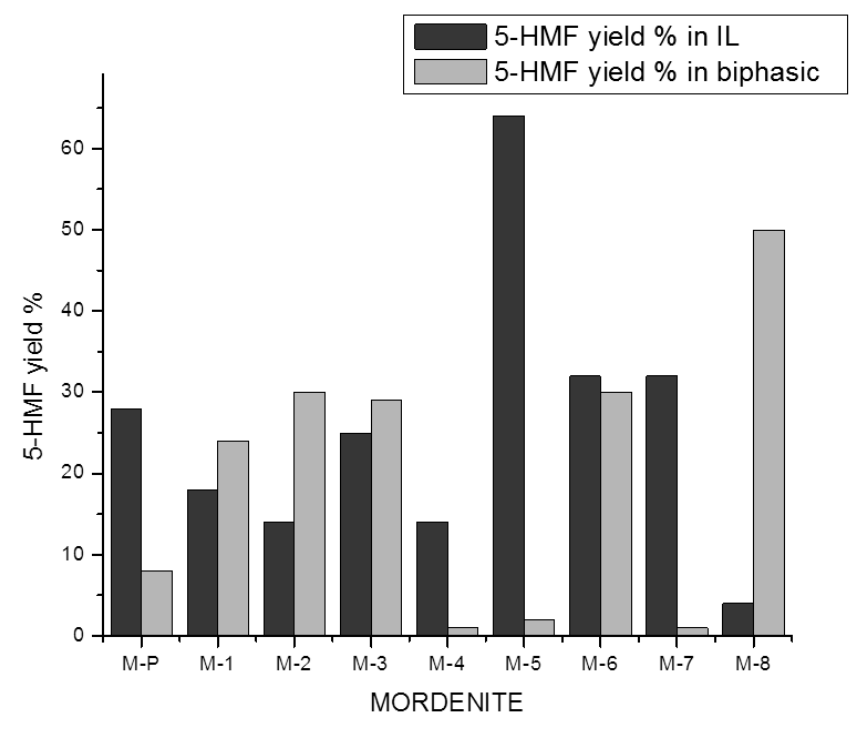

